\title{
Recycled thermoplastics modified bitumen improved with thermoplastic elastomer
}

\author{
Nacer Akkouri ${ }^{1,}{ }^{*}$, Khadija Baba $^{1}$, Sana Simou ${ }^{1}$, Latifa ELfarissi $^{2}$, and Abderrahman Nounah ${ }^{1}$ \\ ${ }^{1}$ Mohammed V University, 10090 Rabat, Morocco \\ ${ }^{2}$ Technical Centers for Plastics and Rubber (CTPC), 20150 Casablanca, Morocco
}

\begin{abstract}
The use of different types of recycled plastic waste such as recycled polypropylene (PP), recycled low-density polyethylene (LDPE) and recycled polystyrene (PS), as raw materials for bitumen modification is known. However, the mechanical and thermal properties of recycled plastic waste modified bitumen (RPMB) are lower than those of the pure plastic modified bitumen. Therefor this paper aims to study the mechanical and thermal properties improvement of the RPMB with the use of a commercial elastomer styrene-butadiene-styrene (SBS). Initially conventional 35/50 quality bitumen was mixed with different percentages of LDPE, PS and PP, and then doped with commercial SBS. Basic rheological parameters such as penetration, softening point, elastic recovery and penetration index showed the changes caused by each rate of polymer addition to pure bitumen. The tests showed that the penetrability of the modified bitumen decreases and its softening point and elastic recovery increases, resulting in a decrease in the thermal sensitivity of the new bitumen mixture.
\end{abstract}

Keywords: Polymers, recycled plastic waste, SBS, modified bitumen, bitumen.

\section{Introduction}

The packaging is the most important sector of the plastics processing market in Morocco, where three types are widely used, namely Polypropylene, Low Density Polyethylene and Polystyrene known as thermoplastics [1-2], that generate big volumes of plastic waste, among which a large amount is under recycled. Therefor the recovery and the reuse of recycled plastic waste in morocco has a major impact on the environment, on the one hand, in order to minimize the rate of plastics abandoned in nature and, on the other hand, on the Moroccan economy since the plastics industry import the majority of its needs in raw materials.

The enlargement of road infrastructure in Morocco have been given a great importance during the last 25 years because of its impact on the country's economic, social and tourism development. As a result asphalts are used extensively in several applications especially in the paving industry[3], where bituminous binders play a key role determining the performance of bituminous asphalt [4] in order to face the factors responsible of asphalt pavement failure which are the higher traffic volume, and the higher axle loads, combined with the significant variations in temperatures [5].

The investigations have shown that, thermoplastics increase the stiffness at high temperatures of bitumen mixtures as well as cracking resistance at low temperatures, and upturn fatigue resistance of bitumen [6-7]. However, the Recycling process of the thermoplastic causes the breaking of chains so the structure of the polymer changes. As a result, the physical characteristics of the recycled polymer, are different and generally lower than those of the virgin polymer[8]. In order to improve the properties of the recycled polymer and have significant elastomeric characteristics for the mixture, we used in this case unsaturated thermoplastic elastomer Styrene-butadienestyrene (SBS) block copolymers, for which both flexible and thermoplastic qualities are assigned. These are the most widely used polymers as bitumen modifiers. They improve the elastic recovery capacity of asphalt and, consequently, its resistance to permanent deformation. [9-10].

Therefore, with the new approach of Morocco on getting into the circular economy and wanting to increase its overall recycling rate, it will be interesting to reuse more efficiently plastics waste for road construction in order to develop the solid waste management while improving the characteristics of bitumen mixtures used in road construction. As a result, and in accordance to this perspective, this paper aims to characterize SBS and recycled plastic waste mixture modified bitumen SBS/RPMB in comparison with RPMB mixtures and its impact on enhancing the performance of the bitumen mixture used in road construction in Morocco.

Corresponding author: akkouri.nacer@gmail.com 


\section{Materials and methods}

The 35/50 penetration grade bitumen and the linear block copolymer based on Styrene-butadiene-styrene (SBS), physical properties are collated in

Table 1 and Table 2. The plastic waste used are separated into 3 categories, namely Polypropylene, Low Density Polyethylene and Polystyrene, for which we conducted Physio-chemical tests which are determination of tensile properties, hardness, density and thermal analysis of polymers, that allowed us to determine the basic characteristics of the recycled material mixture corresponding to each category. Its Physio-chemical properties are summarized in Table 3.

In order to be correctly incorporated into the bitumen, the plastic waste was crushed, extruded and granulated with a cylindrical shape of about 3-4 $\mathrm{mm}$ long to obtain an optimal size to feed the bitumen mixer Fig. 1 .

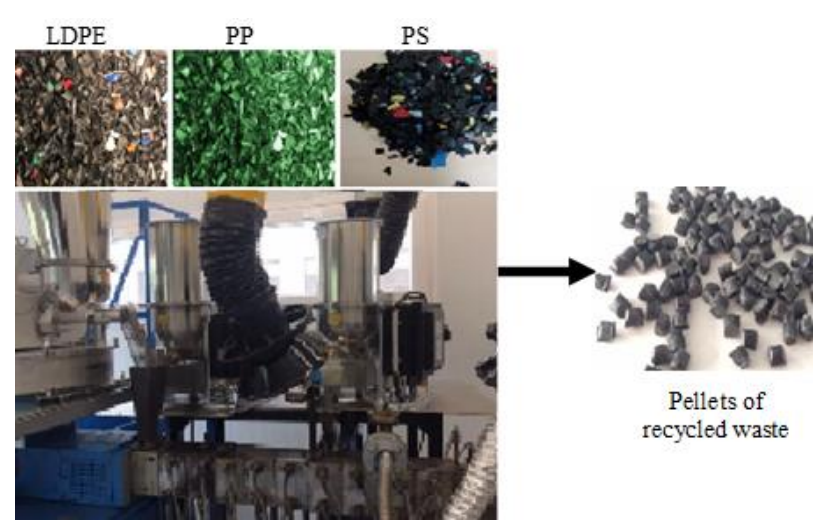

Fig. 1. LDPE, PP and PS crushed, extruded and granulated with a cylindrical shape (3-4 $\mathrm{mm})$
Table 1: Main properties of bitumen.

\begin{tabular}{|c|c|c|}
\hline Properties & Test method & Results \\
\hline $\begin{array}{c}\text { Penetration, } \mathrm{T}=25^{\circ} \mathrm{C} \\
(10-1 \mathrm{~mm})\end{array}$ & EN 1426 & 46.6 \\
\hline $\begin{array}{c}\text { R\&B Softening point } \\
\left({ }^{\circ} \mathrm{C}\right)\end{array}$ & EN 1427 & 52 \\
\hline Density $(\mathrm{g} / \mathrm{cm} 3)$ & EN ISO 3838 & 1.0501 \\
\hline Ductility at $25^{\circ} \mathrm{C}(\mathrm{cm})$ & EN 13589 & $>150$ \\
\hline
\end{tabular}

Table 2 : Properties of SBS

\begin{tabular}{|c|c|c|c|c|}
\hline $\begin{array}{c}\text { S/B } \\
\text { ratio }\end{array}$ & $\begin{array}{c}\text { Oil } \\
\text { content, } \\
\%\end{array}$ & $\begin{array}{c}\text { Elongation, } \\
\mathbf{\geq} \%\end{array}$ & $\begin{array}{c}\text { Hardness } \\
\text { shore, } \mathbf{A}\end{array}$ & $\begin{array}{c}\text { Melt flow } \\
\text { rate, g/10 } \\
\text { min }\end{array}$ \\
\hline $30 / 70$ & 0 & 800 & 72 & $<1$ \\
\hline
\end{tabular}

For the preparation of Recycled Plastic Modified Bitumen (RPMB) we used melt-blending technique. The pure bitumen $(3000 \mathrm{~g})$ was heated in oven until its fluid condition was reached at $170^{\circ} \mathrm{C}(\mathrm{EN} \mathrm{14023)}$ then the polymer was slowly added FIG. 1 (b). The speed of the mixer was kept between $5000 \mathrm{rpm}$ and $10000 \mathrm{rpm}$, and temperature, between $170^{\circ} \mathrm{C}$ and $180^{\circ} \mathrm{C}$. The concentration of PP, LDPE and PS were taken as $5 ; 6$ and $7 \%$ by weight of the bitumen Fig. 2 .

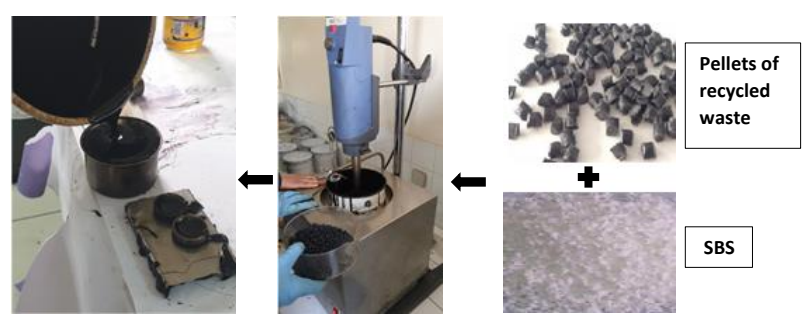

Fig. 2. Melt-blending technique and testing of mixtures

Table 3: Main properties of waste plastic

\begin{tabular}{|c|c|c|c|c|}
\hline Properties & $\begin{array}{c}\text { Test } \\
\text { method }\end{array}$ & $\begin{array}{c}\text { Polypropylene } \\
\text { (PP) }\end{array}$ & $\begin{array}{c}\text { Low Density } \\
\text { Polyethylene } \\
\text { (LDPE) }\end{array}$ & $\begin{array}{c}\text { High impact } \\
\text { polystyrene } \\
\text { (PS) }\end{array}$ \\
\hline $\begin{array}{l}\text { Stress at break } \\
\quad(\mathrm{MPa})\end{array}$ & \multirow{3}{*}{ ISO $527-1$} & 28.060 & 27.860 & 29.620 \\
\hline $\begin{array}{c}\text { Elongation at } \\
\text { break }(\%)\end{array}$ & & 3.300 & 5.480 & 1.840 \\
\hline $\begin{array}{c}\text { Young's } \\
\text { modulus (MPa) }\end{array}$ & & 894.000 & 685.600 & 1392.000 \\
\hline $\begin{array}{c}\text { Hardness Shore } \\
\text { D } \\
\end{array}$ & ISO 48-5 & 63.400 & 67.480 & 72.700 \\
\hline Density $(\mathrm{g} / \mathrm{cm} 3)$ & $\begin{array}{l}\text { ISO } 1183 \\
\text { method A }\end{array}$ & 0.879 & 0.870 & 1.061 \\
\hline $\operatorname{Tf}\left({ }^{\circ} \mathrm{C}\right) *$ & \multirow{2}{*}{$\begin{array}{c}\text { (DSC } \\
\text { machine) } \\
\text { ISO 11357 }\end{array}$} & 163 & 125 & 159 \\
\hline $\operatorname{Tg}\left({ }^{\circ} \mathrm{C}\right) * *$ & & - & - & 99 \\
\hline
\end{tabular}

*The melting temperature, ${ }^{* *}$ The glass transition temperature. 
For the preparation of Styrene-butadiene-styrene and Recycled Plastic Modified Bitumen (SBS/RPMB), we followed the same technique used for the preparation of the previous modified bitumen and we took as additive $3 \%$ of each recycled plastic waste (PP, LDPE, and PS) for which we added respectively $2 \%, 3 \%$ and $4 \%$ of SBS calculated by weight of the bitumen It was observed that over $7 \%$ of the polymer, the modified binder becomes visually heterogeneous and the modification process becomes difficult to achieve.

The mixing was continuous for $40 \mathrm{mins}-1 \mathrm{hr}$ to produce homogenous mixtures. The recycled plastic modified bitumen (RPMB) was then sealed in containers and stored for further testing.

According to the literature, 3 to $7 \%$ by weight of Polymers are usually used to modify bitumen binders, with respect to the bituminous phase [6-11]. In this study, we had two categories of bitumen mixtures one with only the recycled plastic wastes PP, LDPE and PS respectively at $5 \%, 6 \%$ and $7 \%$, and the second category is composed of the recycled plastic waste PP, LDPE and PS at $3 \%$ where each one was mixed respectively with $2 \%, 3 \%$ and $4 \%$ of SBS. It was observed that, over $7 \%$ of the polymer, the modified binder becomes visually heterogeneous and the modification process becomes difficult to achieve.

The ring and ball (R\&B) or softening point test (SP), and penetration (Pen25) test were performed based on the EN 1427 and EN 1426 standard respectively, to evaluate the softening point and hardness of bitumen for the two categories of bitumen mixtures. Then to determine the elastic recovery of bituminous binders, we used a ductilimeter at the test temperature according to the EN 13398 in order to assess the extent to which a substance returns to its original form after application and relaxation of stress.

Regarding the repeatability of the tests, the three results of the penetration test were kept under $2 \mathrm{dmm}$ and the difference between two results of $\mathrm{R} \& \mathrm{~B}$ and elastic recovery test were kept under $1.5^{\circ} \mathrm{C}$ and $4 \%$ respectively. In addition, sensitivity of the RPMBs has been calculated in terms of penetration index (PI) using the equation (1) according to the EN 12591.

$$
P I=\frac{\left(1952-500 \times \log \left(\mathrm{Pen}_{25}\right)-20 \mathrm{SP}\right.}{50 \times \log \left(\mathrm{Pen}_{25}\right)-5 \mathrm{P}-120}
$$

\section{Results and discussion}

\subsection{Penetration}

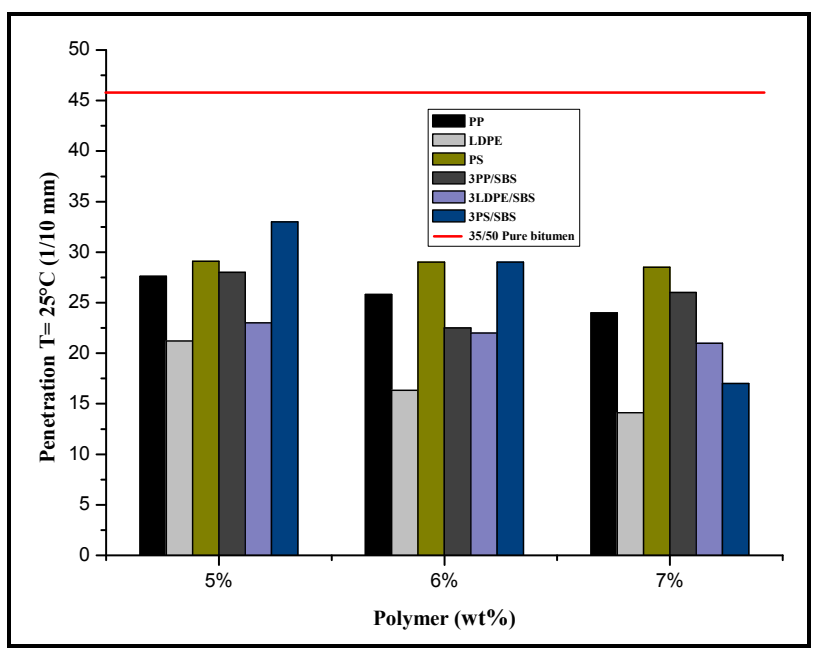

Fig. 3 illustrates the effect of plastic waste concentration and SBS on penetration. The penetrability of modified bitumen decreases with the addition of recycled plastic waste, from 46.6 for pure bitumen to $24,14.1,28.5,26$, 21 and 17 respectively for PP, LDPE, PS, PP/SBS, LDPE/SBS and PS/SBS with $7 \%$ added polymer, we also found that the penetration of bitumen modified by LDPE/SBS and PP/SBS increases slightly compared respectively to LDPE and PP, confirming the tendency of its recycled polymers to essentially influence the hardness of the bitumen [12-1-14] . However, the modification by PS/SBS gives a greater decrease in penetrability than the modification by PS; because the morphology of the SBS copolymers consists of a twophase system with domains of vitreous polystyrene (PS) linked together by rubbery polybutadiene (PB) segments. Generally, when mixing the components at high temperature, the bonds of SBS are weakened and make SBS and PS transformable in the molten state [15-16-6]. the critical network between the binder and the polymer is formed, which reduces penetrability by increasing rigidity, as an indication of resistance to rutting[17].

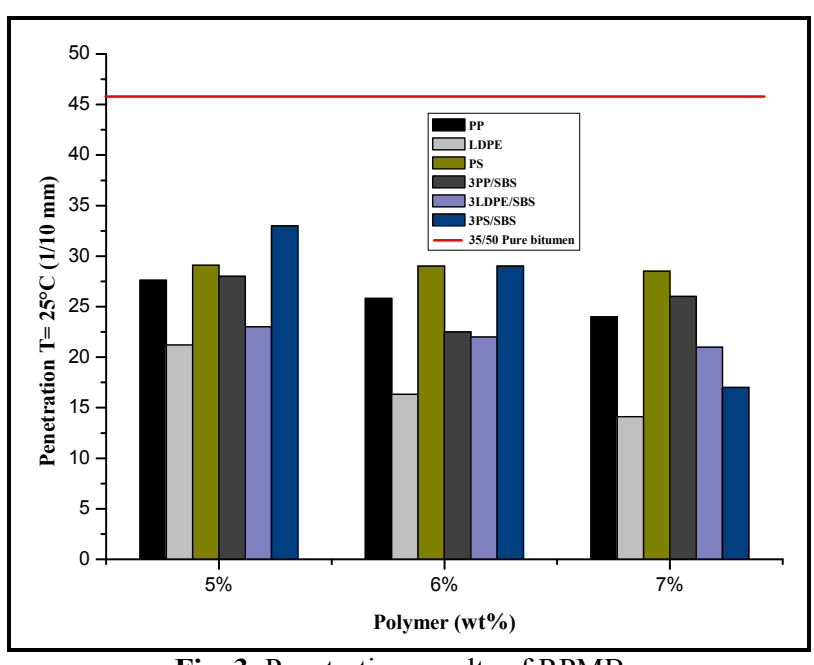

Fig. 3. Penetration results of RPMBs

\subsection{Softening point}

\footnotetext{
Corresponding author: akkouri.nacer@gmail.com
} 
Fig. 2 shows that the softening point was slightly increased with the addition of the polymer mixtures to range between $61^{\circ} \mathrm{C}$ and $74^{\circ} \mathrm{C}$ for $\mathrm{RPMB}$ at $7 \%$ in respectively $\mathrm{PP}, \mathrm{PS}, \mathrm{PP} / \mathrm{SBS}, \mathrm{LDPE} / \mathrm{SBS}$ and $\mathrm{PS} / \mathrm{SBS}$ except for the RPMB at $7 \%$ of LDPE binder where the softening point increased considerably to reach $87^{\circ} \mathrm{C}$, which can be interpreted positively especially in enhancing the performance at high temperature and improving the RPMB and the SBS/RPMB mixtures characteristics in term of rutting [18]. According to these results the adding of SBS to the RPMB mixtures impacted positively the softening point of the mixtures except for LDPE/RPMB where the softening point decreased but still in good position in comparison with the pure bitumen softening point., which could be explained by the network structure formed by SBS in the RPMB's mixtures [19].

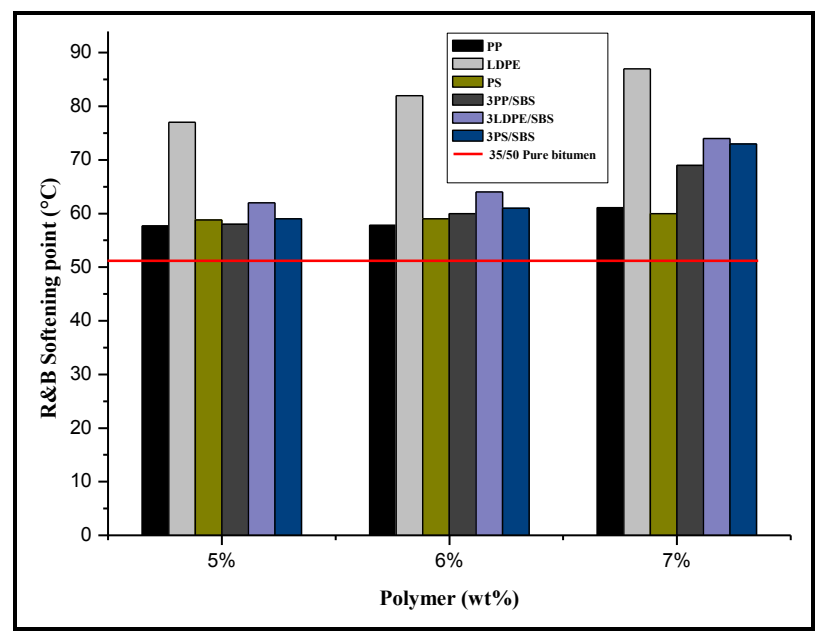

Fig. 4. Softening point results of RPMBs

\subsection{Elastic recovery}

The elastic recovery is an interesting method for the assessment if the addition of recycled plastic waste to pure bitumen provides significant elastomeric characteristics for the binder [3] . According to the test results in

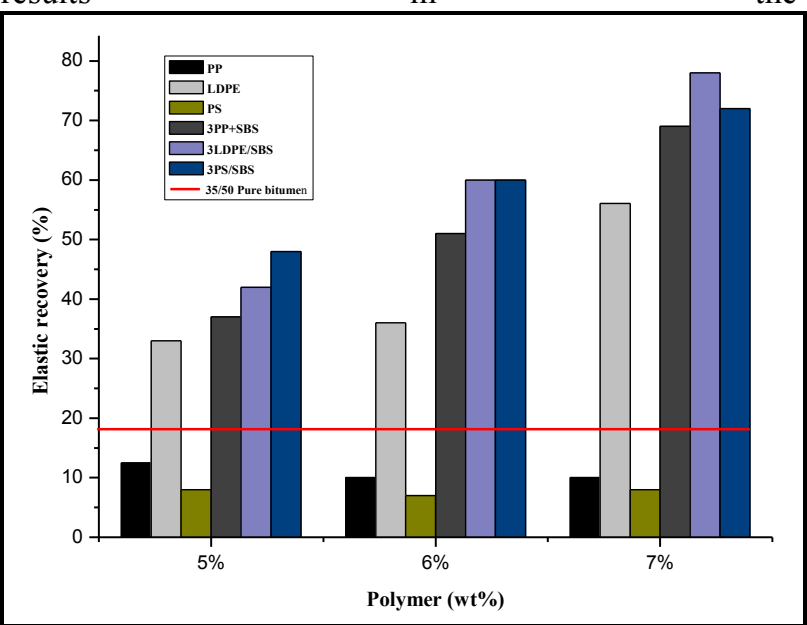

Fig. 5, we found that it decreased for the RPMB with PP and PS, except for the case of RPMB with LDPE but these three mixtures reached the limit of rupture prematurely, and on the contrary for the RPMB with $\mathrm{PP} / \mathrm{SBS}, \mathrm{LDPE} / \mathrm{SBS}$ and PS/SBS the elastic recovery increased considerably to reach $80 \%$ without rupture which confirms the improvement that the addition of the SBS to the polymer mixture brings to the properties of the SBS/RPMB. This may be due network structure formed by SBS in the modified bitumen, which enhances cracking resistance at low temperatures of modified bitumen [7] .

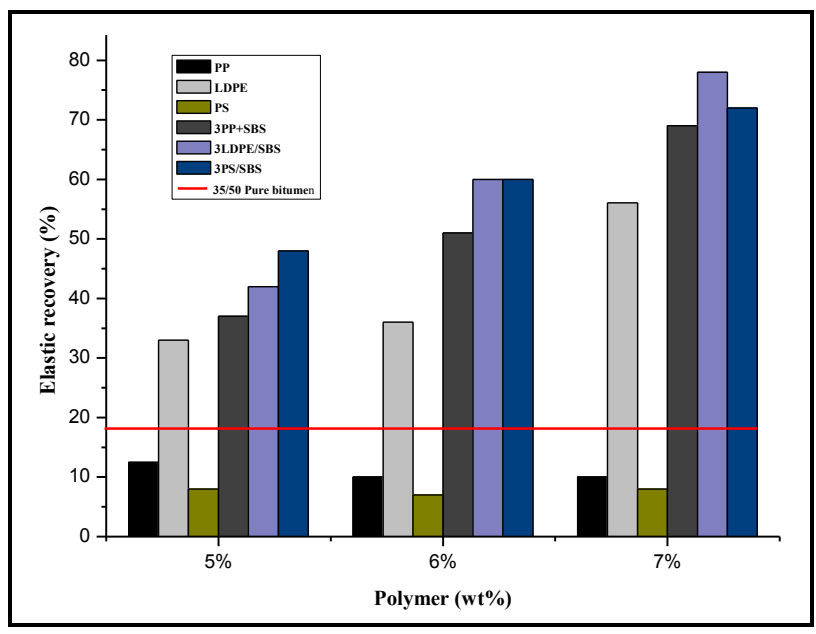

Fig. 5. Elastic recovery results of RPMBs

\subsection{Penetration index}

The penetration index PI can help determine the temperature susceptibility of the bitumen according to Pfeiffer and Van Doormaal [20], this index shows the deviation of the binder behavior from Newtonien to Non-Newtonien. The penetration index of bitumen ranges between +1 and -1 for road construction. When PI goes under -2 this shows a Newtonian behavior with more temperature susceptibility, and when PI is greater than +2 , the bitumen binder is less brittle with high elastic properties and with more susceptibility to low temperature [14-20]. As showed in the

Fig. 6 at the addition of $6 \%$ of recycled plastic waste and SBS/RPMBs the PI increased slightly for all mixtures without breaking the +1 and -1 barriers, except for the LDPE that increased considerably to reach and exceed +2 , which means that the bitumen binder is less brittle with high elastic properties and with more susceptibility to low temperature. At the addition of $7 \%$ of recycled plastic waste and SBS/RPMBs, PI increased but still at 
the pure bitumen PI interval except for LDPE and LDPE/SBS.

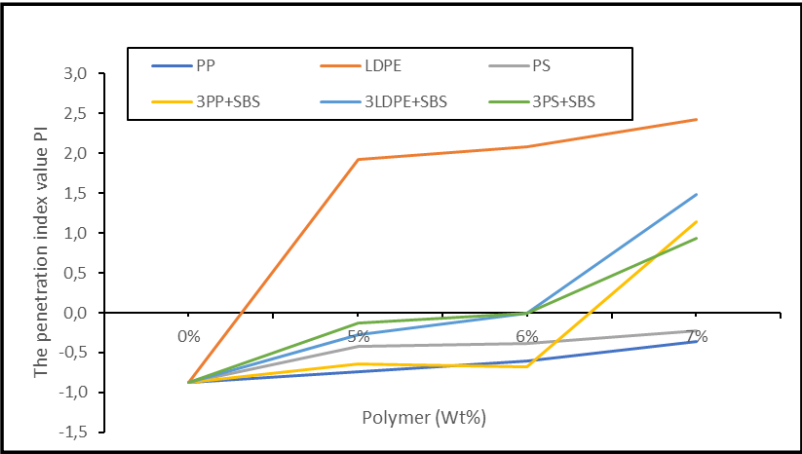

Fig. 6. Penetration index values of RPMBs

\section{Conclusion}

The Improvement of pure bitumen characteristics have been studied when 5, 6 and 7\% wt of recycled PP, LDPE and PS is added into the $35 / 50$ base bitumen. Then the enhancement of those characteristics by the use of the SBS in the modification along with the recycled plastic waste is analyzed, where 2, 3 and $4 \%$ wt of SBS was mixed with $3 \%$ wt of PP, LDPE and PS to form respectively 5,6 and $7 \%$ wt of the additive added to $35 / 50$ base bitumen. Conventional physicochemical characteristics like penetration, softening point, elastic recovery and penetration index have been determined. As far as penetration concerned, the use of SBS in the modification binder reduced considerably the penetrability of SBS/RPMB at $25^{\circ} \mathrm{C}$, which indicates that the bitumen mixture is highly resistant to deformation at the same temperature compared to $35 / 50$ base bitumen. For the softening point, the study showed an increase of more than $30 \%$ by the use of SBS with recycled plastics as modification agent, which indicates that the bituminous mixture is more resistant at high temperature and more resistant to rutting. Thus, the study showed an increase of the PI for the bituminous mixture with the use of SBS and recycled plastic mixture additive, which indicates less susceptibility of the mixture to high temperature. Regarding the elastic recovery, the tests showed that the use of SBS increased considerably the elastomeric characteristics of the mixture to reach more than $70 \%$ without creating premature rupture at $7 \% \mathrm{wt} \mathrm{SBS} / \mathrm{RPMB}$ that confirms the properties SBS brings to the bituminous mixture.

\section{Acknowledgments}

The authors would like to acknowledge the Technical Centre for Plastics and Rubber (CTPC) and Public laboratory for tests and studies - Center for Studies and Research of Transport Infrastructures (CERIT), Morocco, for providing opportunities for experimental collaboration, we also thank to BITUMA Company for providing research facilities.

\section{References}

1. PlasticsEurope, (2017)

2. N. Singh, D. Hui, R. Singh, I. P. S. Ahuja, L. Feo, and F. Fraternali, Composites Part B: Engineering 115, 409 (2017)

3. R. N. Hunter, A. Self, J. Read, and Shell International Petroleum Co, editors, The Shell Bitumen Handbook, 6. ed (ICE Publishing/Telford, London, 2015)

4. Z. Yao, J. Zhang, F. Gao, S. Liu, and T. Yu, Construction and Building Materials 170, 217 (2018)

5. P. J. Carreau, M. Bousmina, and F. Bonniot, The Canadian Journal of Chemical Engineering 78, 495 (2000)

6. T. Alataş and M. Yilmaz, Construction and Building Materials 42, 161 (2013)

7. J. Zhu, B. Birgisson, and N. Kringos, European Polymer Journal 54, 18 (2014)

8. A. V. Shenoy, D. R. Saini, and V. M. Nadkarni, Polymer 24, 722 (1983)

9. T. Wang, T. Yi, and Z. Yuzhen, Petroleum Science and Technology 28, 764 (2010)

10. G. Polacco, S. Berlincioni, D. Biondi, J. Stastna, and L. Zanzotto, European Polymer Journal 41, 2831 (2005)

11. A. Behnood and M. Modiri Gharehveran, European Polymer Journal 112, 766 (2019)

12. P. Kumar, S. Chandra, and S. Bose, International Journal of Pavement Engineering 7, 63 (2006)

13. S. Tapkın, A. Çevik, and Ü. Uşar, Expert Systems with Applications 36, 11186 (2009)

14. N. Z. Habib, I. Kamaruddin, M. Napiah, and I. M. Tan, International Journal of Civil and Environmental Engineering 4, 5 (2010)

15. G. Wen, Y. Zhang, Y. Zhang, K. Sun, and Y. Fan, Polymer Testing 21, 295 (2002)

16. J. Oliver, K. Y. Khoo, and K. Waldron, Road Materials and Pavement Design 13, 104 (2012)

17. Y. Yildirim, Construction and Building Materials 21, 66 (2007)

18. M. E. Abdullah, N. A. Ahmad, R. P. Jaya, N. A. Hassan, H. Yaacob, and M. R. Hainin, IOP Conference Series: Materials Science and Engineering 204, 012016 (2017)

19. N.F. Ghaly, Journal of Applied Sciences Research 4, $11(2008)$

20. R. John and W. David, The Shell Bitumen Handbook, 5th ed. (2003) 